\title{
Novel Bifunctional Zn-Sn Composite Oxide Catalyst for the Selective Synthesis of Glycerol Carbonate by Carbonylation of Glycerol with Urea
}

\author{
Pandian Manjunathan, ${ }^{[a]}$ Raman Ravishankar, ${ }^{[b]}$ and Ganapati V. Shanbhag ${ }^{*[a]}$
}

\begin{abstract}
A novel $\mathrm{Zn}-\mathrm{Sn}$ composite oxide is reported as a solid bifunctional catalyst for glycerol carbonylation to give glycerol carbonate in high yields. It was prepared by coprecipitation, solidstate and evaporation methods. Physico-chemical properties of the catalysts were investigated by XRD, $\mathrm{N}_{2}$ sorption, temperature-programmed desorption, SEM, and TEM techniques. Coprecipitation was found to be better than the other two methods for carbonylation of glycerol. Higher activity of the catalyst was attributed to a high amount of active sites. A series of $\mathrm{Zn}$ -
\end{abstract}

Sn composite oxides with different metal contents and effect of calcination on glycerol carbonate synthesis were also studied. The correlation of activity with total active sites of the catalyst was obtained. $\mathrm{Zn}-\mathrm{Sn}$ composite catalyst with $\mathrm{Zn} / \mathrm{Sn}$ molar ratio $=2: 1$ calcined at $600^{\circ} \mathrm{C}$ exhibited $96.0 \%$ glycerol conversion with $99.6 \%$ selectivity towards glycerol carbonate under optimized reaction conditions. The catalyst was recycled four times with a marginal decrease in activity.

\section{Introduction}

Biofuels derived from the sustainable biomass sources have the potential to displace nonrenewable fossil fuels. Among them, biodiesel has gained much attention from the researchers and its production increased greatly in recent years. Glycerol (1,2,3-propanetriol) is an important byproduct produced (10 wt \% referred to the amount of biodiesel) during the synthesis of biodiesel by transesterification of oils and fats. Consequently, the transformation of glycerol into value-added products has stimulated a thirst among the researchers. It made a window of opportunity to transform glycerol into valueadded products through various chemical routes such as esterification, etherification, acetalization, transesterification, carbonylation, dehydration and hydrogenation. The products obtained from these processes are glycerol acetins, glycerol ethers, solketal, glycerol carbonate, acrolein, 1,2-propanediol, and 1,3-propandiol. Because of its diverse applications, the synthesis of glycerol carbonate has been considered an attractive process. ${ }^{[1-5]}$ Hence, the design of green and chemoselective catalysts for these processes is of great interest.

Glycerol carbonate has both direct and indirect applications in various fields thanks to its interesting properties that lie in between cyclic alkylene carbonate and glycerol. The direct ap-

[a] P. Manjunathan, Dr. G. V. Shanbhag

Materials Science Division, Poornaprajna Institute of Scientific Research Bidalur Post, Devanahalli, Bangalore-562164, Karnataka (India) E-mail: shanbhag@poornaprajna.org

[b] Dr. R. Ravishankar

Hindustan Petroleum Green Research and Development Centre Hindustan Petroleum Corporation Ltd. (HPCL) KIADB Industrial Area, Tarabahalli, Hoskote Taluk Bangalore-560067, Karnataka (India)

$\square$ Supporting Information for this article is available on the WWW under http://dx.doi.org/10.1002/cctc.201501088. plications are as biobased solvent, as electrolyte in lithium ion batteries, curing agent, as liquid membrane in gas separation, blowing agent, detergent, and in cosmetics. Indirectly, glycerol carbonate finds application in the synthesis of surfactants, chemical intermediates, and polymers. Glycerol carbonate can be synthesized by different routes, namely, reaction of glycerol with phosgene, transesterification of glycerol with alkyl carbonate, carbonylation of glycerol by urea, and reaction of glycerol with carbon dioxide.

The use of phosgene as a carbonylating agent is inadequate because of its high toxicity and environmentally unfriendly nature. The utilization of carbon dioxide is one among the best processes to obtain glycerol carbonate, but the activation of $\mathrm{CO}_{2}$ requires severe reaction conditions such as high temperature and pressure. Nevertheless, the process produces minimal yield of glycerol carbonate. The reaction of glycerol with alkyl carbonate by transesterification is an attractive approach to synthesize glycerol carbonate. However, high mole ratio of alkyl carbonate is required to get high yield of glycerol carbonate to prevent the reversible reaction, which leads to difficulties in product separation making the entire process nonviable. ${ }^{[6,7]}$

The carbonylation of glycerol using urea as a carbonating agent overcomes the practical difficulties observed earlier. Urea is an inexpensive raw material produced by the reaction of carbon dioxide and ammonia by Bosch-Meiser urea process. Moreover, ammonia, the byproduct in glycerol carbonylation reaction can be utilized for the synthesis of urea by further reacting with carbon dioxide which in turn leads to an atom-efficient and greener process.

Glycerol carbonylation reaction using urea has been studied with different heterogeneous catalysts such as $\mathrm{ZnO}, \mathrm{HTc}-\mathrm{Zn}$ derived from hydrotalcite, Sn-Beta, ${ }^{[8]} \gamma$-zirconium phosphate, ${ }^{[9]}$ 
$\mathrm{Sn}-\mathrm{W}$ mixed metal oxides, ${ }^{[10]} \quad \mathrm{La}_{2} \mathrm{O}_{3}{ }^{[11]} \quad \mathrm{Co}_{3} \mathrm{O}_{4} / \mathrm{ZnO},{ }^{[12]} \mathrm{Au} /$ $\mathrm{Fe}_{2} \mathrm{O}_{3}{ }^{[13]} \mathrm{Sm}_{0.6}{ }^{\mathrm{TPA}},{ }^{[14]} \mathrm{Zn}_{1} \mathrm{TPA}^{,{ }^{[15]}} \mathrm{ZnSn}(\mathrm{OH})_{6}{ }^{[16]} \mathrm{Zn}$-exchanged zeolites, $^{[17]} \mathrm{Zn} / \mathrm{MCM}-41,{ }^{[18]}$ and quaternary ammonium ion exchanged montmorillonite. ${ }^{[19]}$ Among them, the zinc based catalysts have shown a promising activity because of their Lewis acidic nature. Notably, the catalyst with a combination of Lewis acid and base sites showed better performance yielding high amount of glycerol carbonate.

Binary or mixed metal oxides are widely used in industry as well as in academia which constitute the largest family of heterogeneous catalysts for the selective organic transformation reactions. Binary metal oxides are oxygen-containing compounds formed by the combination of two metal cations that may either vary or be defined by a strict stoichiometry. Owing to the presence of $\mathrm{M}^{n+} \mathrm{O}^{m-}$ ion pairs in metal oxide, it is found to exhibit acid-base and redox properties. The extent of basicity depends on the coordination number of oxygen species present in the metal oxides. The metal ions in multimetallic oxides differ in their coordination environment that governs the type of bonding between the cations resulting in synergistic effect. For example; the two different metal cations can be represented as $M_{A}{ }^{n+}$ and $M_{B}{ }^{n+}$ in polyhedra, which connect in various possible ways such as edge- or corner-sharing $\mathrm{M}_{A}-\mathrm{O}$ $M_{B}-O, M_{A}-O-M_{A}-O$ or $M_{B}-O-M_{B}-O$ metal-oxygen chains. This gives different cation environments leading to different active centers and different reactivity towards an approaching molecule. ${ }^{[18,20-22]}$

Herein, we report the bifunctional $\mathrm{Zn}-\mathrm{Sn}$ composite oxide catalyst for the eco-friendly synthesis of glycerol carbonate from glycerol with urea. The influence of catalyst preparation methods towards its catalytic activity was systematically studied by three different routes, namely, coprecipitation, solidstate and evaporation methods. A series of active $\mathrm{Zn}-\mathrm{Sn}$ composite oxide catalysts were prepared with varying $\mathrm{Zn}$-to-Sn molar ratio. Further, the most active $\mathrm{Zn}-\mathrm{Sn}$ composite oxide was treated at different temperatures to vary its catalytic properties. Two decisive catalyst properties, namely, acidity and basicity of the active catalyst were correlated with catalytic activity. The effect of reaction parameters on catalytic activity such as catalyst concentration, reaction temperature, and reaction time was also studied.

\section{Results and Discussion}

The XRD patterns of $\mathrm{Zn}-\mathrm{Sn}$ composite oxides prepared by using three different methods are shown in Figure 1 aand Supporting Information, Figure S.1.1a. Zn-Sn composite oxide prepared through solid-state (SS) and evaporation method (Evp), respectively, showed a main phase of $\mathrm{ZnO}$ and $\mathrm{SnO}_{2}$ along with a little spinel crystalline phase of $\mathrm{Zn}_{2} \mathrm{SnO}_{4}$. Conversely, $\mathrm{Zn}$-Sn composite oxide prepared by coprecipitation method (CoPre) showed the main diffraction peak of spinel structured $\mathrm{Zn}_{2} \mathrm{SnO}_{4}$ with the co-existence of $\mathrm{ZnO}$ and $\mathrm{SnO}_{2}$. The reason for the formation of $\mathrm{Zn}_{2} \mathrm{SnO}_{4}$ as the major component can be explained as follows. The coprecipitation of $\mathrm{Zn}$ and $\mathrm{Sn}$ salts results in mainly a perovskite-type $\mathrm{Zn}-\mathrm{Sn}$ hydroxide as the intermediate before the calcination step. ${ }^{[16]}$ Upon calcination to
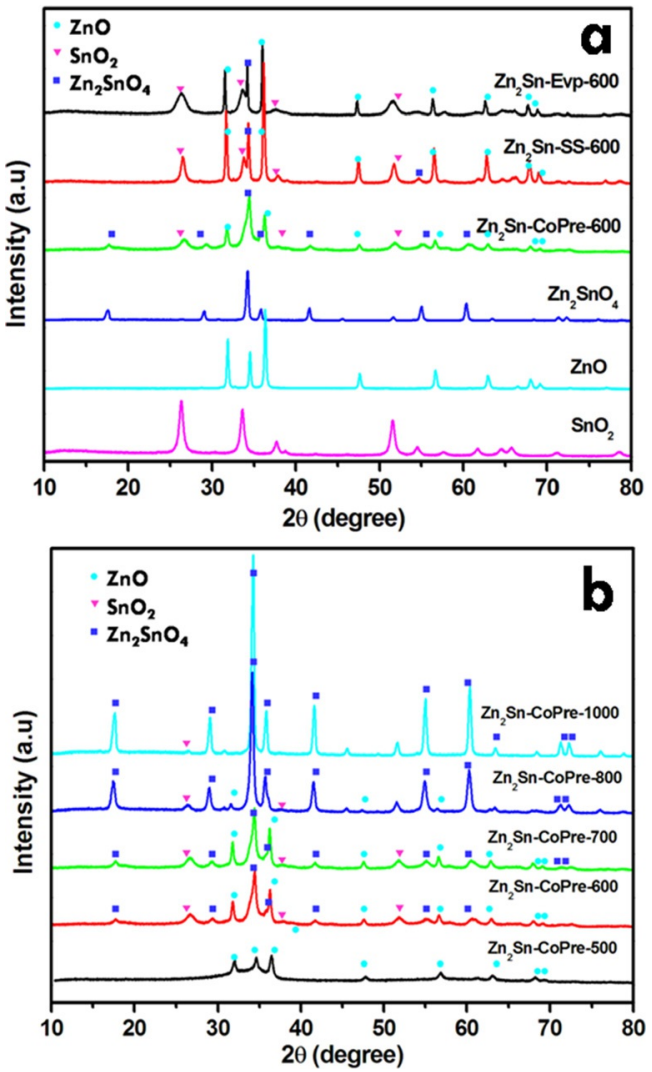

Figure 1. XRD patterns of (a) individual and composite $Z n-S n$ oxides prepared by three different methods with $\mathrm{Zn} / \mathrm{Sn}=2$, (b) $\mathrm{Zn} \mathrm{n}_{2} \mathrm{Sn}$-CoPre catalysts prepared at different calcinations temperatures.

$600^{\circ} \mathrm{C}, \mathrm{Zn}$-Sn hydroxide undergoes dehydroxylation leading to the formation of $\mathrm{Zn}_{2} \mathrm{SnO}_{4}$ spinel.

The XRD patterns of the $\mathrm{Zn}$-rich $\mathrm{Zn}$-Sn composite oxides prepared with coprecipitation method clearly showed the increase of wurtzite-structured $\mathrm{ZnO}$ with increasing of $\mathrm{Zn} / \mathrm{Sn}$ molar ratio in the range of 1-3 as shown in the Supporting Information, Figure S.1.1.b. The result indicates that the catalysts exhibit the combination of $\mathrm{Zn}_{2} \mathrm{SnO}_{4}$ spinel, $\mathrm{ZnO}$, and $\mathrm{SnO}_{2}$ phases.

The XRD patterns of $\mathrm{Zn}_{2} \mathrm{Sn}$-CoPre catalyst calcined at different temperatures are shown in Figure $1 \mathrm{~b}$. It can be seen that the calcination temperature has a significant role in the formation of different phases. $\mathrm{Zn}_{2} \mathrm{Sn}$-CoPre catalyst showed a gradual increase in crystallinity with increasing calcination temperature in the range of $500-1000^{\circ} \mathrm{C}$. The catalyst $\mathrm{Zn} \mathrm{n}_{2} \mathrm{Sn}$-CoPre calcined at $500{ }^{\circ} \mathrm{C}$ showed the existence of only $\mathrm{ZnO}$ phase with lower intensity suggesting the presence of tin oxide in the amorphous state. However, at calcination temperatures of 600 and $700{ }^{\circ} \mathrm{C}$, phases corresponding to $\mathrm{Zn}_{2} \mathrm{SnO}_{4}$ spinel were formed with $\mathrm{ZnO}$ and $\mathrm{SnO}_{2}$ in minor quantities. Further, $\mathrm{ZnO}$ phase disappeared above $800^{\circ} \mathrm{C}$ giving rise to $\mathrm{Zn}_{2} \mathrm{SnO}_{4}$ spinel and $\mathrm{SnO}_{2}$ phases.

The textural properties of $\mathrm{Zn}-\mathrm{Sn}$ composite oxide catalysts are tabulated in Table 1 . The catalysts prepared through the evaporation method showed larger surface area and pore volume than those prepared by the other two routes. The $\mathrm{Zn}-$ 


\begin{tabular}{|c|c|c|c|c|c|c|}
\hline Catalyst & $\begin{array}{l}\text { Calcination } \\
\text { temp. }\left[{ }^{\circ} \mathrm{C}\right]\end{array}$ & $\begin{array}{l}S_{\mathrm{BET}}{ }^{[\mathrm{a}]} \\
{\left[\mathrm{m}^{2} \mathrm{~g}^{-1}\right]}\end{array}$ & $\begin{array}{l}\text { Pore volume }{ }^{[b]} \\
{\left[\mathrm{cm}^{3} \mathrm{~g}^{-1}\right]}\end{array}$ & $\begin{array}{l}\text { Pore size }{ }^{[c]} \\
{[\mathrm{nm}]}\end{array}$ & $\begin{array}{l}\text { Acidity } \\
{\left[\mu \mathrm{mol}_{\mathrm{NH}_{3}} \mathrm{~g}^{-1}\right]^{[\mathrm{d}]}}\end{array}$ & $\begin{array}{l}\text { Basicity } \\
{\left[\mu \mathrm{mol}_{\mathrm{CO}_{2}} \mathrm{~g}^{-1}\right]^{[\mathrm{e}]}}\end{array}$ \\
\hline $\mathrm{ZnO}$ & 600 & 18.9 & 0.022 & 4.6 & 60 & 12 \\
\hline $\mathrm{SnO}_{2}$ & 600 & 16.6 & 0.066 & 15.8 & 30 & 4 \\
\hline $\mathrm{Zn}_{2} \mathrm{SnO}_{4}$ & 600 & 40.0 & 0.150 & 3.7 & 160 & 20 \\
\hline $\mathrm{Zn}_{1} \mathrm{Sn}$-CoPre & 600 & 13.3 & 0.056 & 17.0 & 235 & 52 \\
\hline $\mathrm{Zn}_{3} \mathrm{Sn}$-CoPre & 600 & 17.0 & 0.046 & 10.9 & 256 & 48 \\
\hline $\mathrm{Zn}_{1} \mathrm{Sn}-\mathrm{SS}$ & 600 & 8.9 & 0.055 & 24.7 & 216 & 38 \\
\hline $\mathrm{Zn}_{2} \mathrm{Sn}-\mathrm{SS}$ & 600 & 9.2 & 0.050 & 22.7 & 223 & 45 \\
\hline $\mathrm{Zn}_{1} \mathrm{Sn}-\mathrm{Evp}$ & 600 & 31.5 & 0.132 & 16.7 & 181 & 35 \\
\hline $\mathrm{Zn}_{2} \mathrm{Sn}-\mathrm{Evp}$ & 600 & 33.2 & 0.130 & 16.5 & 210 & 48 \\
\hline $\mathrm{Zn}_{2} \mathrm{Sn}$-CoPre & 500 & 25.0 & 0.052 & 8.4 & 207 & 30 \\
\hline $\mathrm{Zn}_{2} \mathrm{Sn}$-CoPre & 600 & 15.2 & 0.049 & 12.6 & 268 & 61 \\
\hline $\mathrm{Zn}_{2} \mathrm{Sn}$-CoPre & 700 & 14.1 & 0.047 & 13.2 & 240 & 53 \\
\hline $\mathrm{Zn}_{2} \mathrm{Sn}$-CoPre & 1000 & 3.0 & 0.007 & 9.3 & 100 & 7 \\
\hline
\end{tabular}

Sn composite oxides prepared by coprecipitation and solidstate routes gave lower surface area than $\mathrm{ZnO}$, whereas the pore volume was in between that of $\mathrm{ZnO}$ and $\mathrm{SnO}_{2}$. However, a marginal increase in surface area was observed upon increasing the $\mathrm{Zn}$ content in $\mathrm{Zn} / \mathrm{Sn}$ composition for the three catalyst preparation methods. The effect of calcination on $\mathrm{Zn}_{2} \mathrm{Sn}$-CoPre catalysts showed that with increasing calcinations temperature, the surface area and pore volume decline because of the agglomeration of particles.

The amount of acidity in Zn-Sn composite oxide catalysts was determined by temperature-programmed desorption (TPD) technique using ammonia as a probe molecule as tabulated in Table 1. Zn-Sn composite oxide prepared through coprecipitation method contained a higher amount of acidity than the composite oxides prepared by other preparation methods. The total acidity of catalysts prepared by different methods decreased in the order: coprecipitation $>$ solid state $>$ evaporation.

A gradual increase in total acidity was observed with the increase in $\mathrm{Zn} / \mathrm{Sn}$ molar ratio from 1 to 2 . Amongst the catalysts, $\mathrm{Zn}_{2} \mathrm{Sn}$-CoPre-600 showed the highest amount of acidity. In contrast, further increase in $\mathrm{Zn} / \mathrm{Sn}$ molar ratio to 3 gave a marginal decrease of acidity.

The presence of basic sites in $\mathrm{Zn}-\mathrm{Sn}$ composite oxides was investigated by $\mathrm{CO}_{2}$ TPD and the amount of basicity is represented in Table 1. Basically, the lattice oxygens present on the metal oxide surface are considered to act as Lewis basic sites. ${ }^{[22]}$ As observed for $\mathrm{NH}_{3} \mathrm{TPD}, \mathrm{Zn}-\mathrm{Sn}$ composite oxides also showed an increase of basic sites with increase in $\mathrm{Zn} / \mathrm{Sn}$ molar ratio from 1 to 2 , however, further increase of $\mathrm{Zn} / \mathrm{Sn}$ to 3 resulted in the decrease of total basicity. The $\mathrm{Zn}_{x} \mathrm{Sn}$-CoPre catalysts exhibited a greater amount of basic sites than the catalysts prepared by other methods, and $\mathrm{Zn}_{2} \mathrm{Sn}$-CoPre-600 showed highest amount of basicity.

The results from $\mathrm{NH}_{3}$ and $\mathrm{CO}_{2}$ TPD of $\mathrm{Zn}_{2} \mathrm{Sn}$-CoPre catalysts obtained from different calcination temperatures exhibited interesting results (Table 1). The increase in calcination tempera- ture from $500-600^{\circ} \mathrm{C}$ results in an increase of total active sites (acidity and basicity) owing to the formation of mixed phase as observed in XRD pattern. However, a further increase in calcination temperature above $600^{\circ} \mathrm{C}$ leads to a decrease in the amount of total active sites (acidity and basicity). This could be attributed to the decreased amount of metal-oxygen pairs on the surface caused by the decrease of surface area in $\mathrm{Zn}-\mathrm{Sn}$ composite oxide. ${ }^{[22]}$ As a result, $\mathrm{Zn}_{2} \mathrm{Sn}$-CoPre-600 catalyst possesses a relatively higher amount of total active sites than other samples.

SEM analysis of $\mathrm{Zn}-\mathrm{Sn}$ composite oxide catalysts revealed the particle size and morphology as shown in Figure 2. Depending on the adopted catalyst preparation methods, the morphology and particle sizes varied. Amongst them, $\mathrm{Zn}_{1} \mathrm{Sn}$ Evp-600 showed larger particle sizes ranging between 2 and $30 \mu \mathrm{m}$ (average of $8.3 \mu \mathrm{m}$ ), possessing nonuniform particles with rough edge surface. Irregular morphology of uniformly dispersed $\mathrm{ZnO}$ on the $\mathrm{SnO}_{2}$ surface was observed with $\mathrm{Zn}_{1} \mathrm{Sn}$ SS-600. And the particle size was in the range of 0.4-1.6 $\mu \mathrm{m}$. In the case of $\mathrm{Zn}_{1} \mathrm{Sn}$-CoPre- 600 , the particle size was in the range of $0.5-4 \mu \mathrm{m}$ with octahedral morphology containing an average particle size of $1.6 \mu \mathrm{m}$.

The change in $\mathrm{Zn} / \mathrm{Sn}$ mole ratio prepared by the coprecipitation method resulted in a different morphology with varying particle size (Figure $2 c, d, f$ ). $\mathrm{Zn}_{2} \mathrm{Sn}$-CoPre-600 possessed cubic shape with the particle size ranging from 0.8 to $2.5 \mu \mathrm{m}$ and the average particle size was $1.6 \mu \mathrm{m}$. $\mathrm{Zn}_{3} \mathrm{Sn}$-CoPre- 600 exhibited octahedral morphology with particle sizes in the range of 0.9-2.5 $\mu \mathrm{m}$ (average size $=1.7 \mu \mathrm{m}$ ).

Interestingly, SEM images of $Z_{x}$ Sn-CoPre-600 (x=1-3) showed some protuberance on the surface of octahedral or cubic morphology. It could be caused by the growth of $\mathrm{ZnO}$ by the secondary nucleation from the excess of $Z n$ species. As the $\mathrm{Zn} / \mathrm{Sn}$ molar ratio increases from 2 to 3 , the formation of $\mathrm{ZnO}$ from secondary nucleation masks the octahedral surface. Moreover, the particle size of $\mathrm{ZnO}$ formed on the cubic or octahedral surface lies in the nano regime $(<100 \mathrm{~nm})$ and it is 


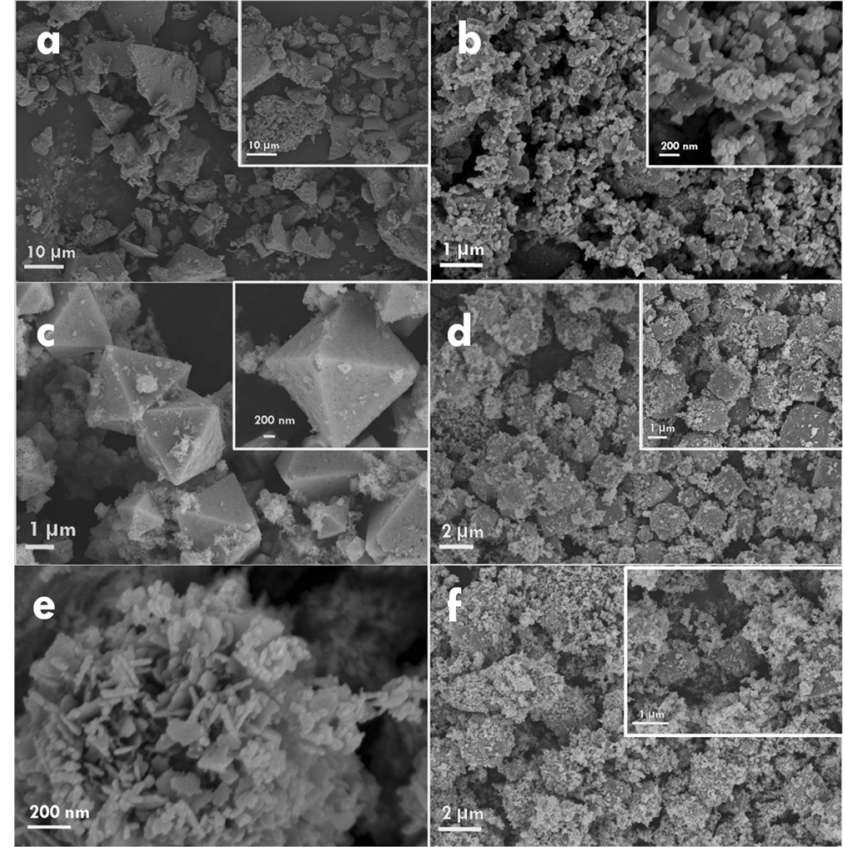

Figure 2. SEM images of (a) Zn $n_{1} S n-E v p-600$, (b) Zn $n_{1} S n-S S-600$, (c) Zn 1 SnCoPre-600, (d) Zn $n_{2}$ Sn-CoPre-600, (e) Zn $n_{2} S n-C o P r e-600$ (secondary nucleation on cubic surface), and (f) $\mathrm{Zn}_{3} \mathrm{Sn}-$ CoPre- 600 .

composed of weakly agglomerated small-flake-like particles. (Figure 2e).

TEM images of $\mathrm{Zn}_{2} \mathrm{Sn}$-CoPre-600 are shown in Figure $3 \mathrm{a}-\mathrm{f}$. The TEM images in Figure $3 \mathrm{a}$ and $3 \mathrm{~b}$ show cubic morphology with the size ranging from 0.5 to $2 \mu \mathrm{m}$ along with other particles in the nanosized range. The corresponding high-resolution (HR) TEM micrograph of the cubic morphology is shown in Figure $3 c$, which reveals well-defined lattice fringes with $d$-spacings of 0.33 and $0.28 \mathrm{~nm}$ corresponding to (220) and (311) planes of $\mathrm{Zn}_{2} \mathrm{SnO}_{4}$, respectively. ${ }^{[23]}$ In Figure $3 \mathrm{~d}$, the TEM image of nanoparticles grown near the cubic morphology is shown. The HRTEM image of the nanoparticles shows the $d$-spacing of 0.33 and $0.28 \mathrm{~nm}$ corresponding to (110) and (100) planes of $\mathrm{SnO}_{2}$ and $\mathrm{ZnO}$, respectively, confirming the presence of nanocrystalline particles of the $\mathrm{SnO}_{2}$ and $\mathrm{ZnO}$.

\section{Catalytic activity studies}

\section{Performance of $\mathrm{Zn}$-Sn composite metal oxide catalyst}

The catalytic behavior of $\mathrm{Zn}_{1} \mathrm{Sn}$ composite oxides prepared through different routes was evaluated for the carbonylation reaction of glycerol with urea and the results are tabulated in Table 2 . The reaction without catalyst resulted in only $32 \%$ of glycerol conversion with $95 \%$ glycerol carbonate selectivity. Pure oxides of $\mathrm{Zn}$ and $\mathrm{Sn}$, and bimetallic oxides of $\mathrm{Zn}$ and $\mathrm{Sn}$ were individually tested as catalysts. These oxides showed moderate activity of $66.4 \%(\mathrm{ZnO}), \quad 39.6 \%\left(\mathrm{SnO}_{2}\right)$, and $50 \%$ $\left(\mathrm{Zn}_{2} \mathrm{SnO}_{4}\right)$ glycerol conversion with glycerol carbonate selectivity of 98,99 and $96 \%$ respectively. The other minor products formed during the reaction were glycerol carbamate, glycidol,
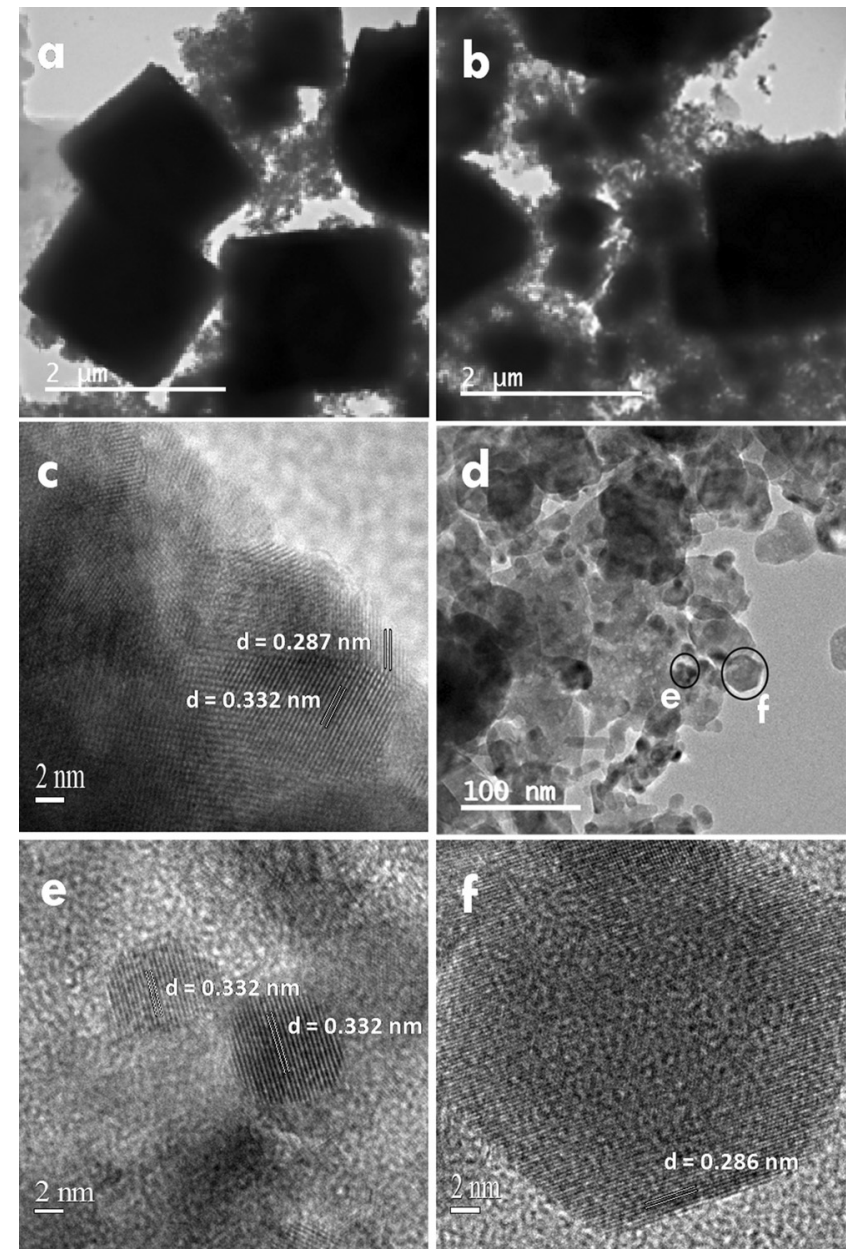

Figure 3. TEM and HRTEM images of $\mathrm{Zn}_{2} \mathrm{Sn}$-CoPre-600: (a) and (b) TEM image; (c) HRTEM image of cubic particles; (d) TEM image of secondary particles; (e) HRTEM image of the small circled area in (d); (f) HRTEM image of thelarge circled area in (d).

\begin{tabular}{|c|c|c|c|c|}
\hline Catalyst & $\begin{array}{l}\text { Total active } \\
\text { sites } \\
{\left[\mu \mathrm{molg}^{-1}\right]^{[\mathrm{b}]}}\end{array}$ & $\begin{array}{l}\text { Glycerol } \\
\text { conversion } \\
\text { [wt \%] }\end{array}$ & $\begin{array}{l}\text { GlyC } \\
\text { selectivity } \\
\text { [wt \%] }\end{array}$ & $\begin{array}{l}\text { GlyC } \\
\text { yield } \\
\text { [wt \%] }\end{array}$ \\
\hline blank & - & 32.0 & 95.8 & 30.6 \\
\hline $\mathrm{ZnO}$ & 72 & 66.4 & 98.1 & 65.1 \\
\hline $\mathrm{SnO}_{2}$ & 34 & 39.6 & 99.0 & 39.2 \\
\hline $\mathrm{Zn}_{2} \mathrm{SnO}_{4}$ & 180 & 50.0 & 96.0 & 48.0 \\
\hline $\mathrm{Zn}_{1} \mathrm{Sn}-\mathrm{CoPre}-600$ & 287 & 88.0 & 99.2 & 87.3 \\
\hline $\mathrm{Zn}_{1} \mathrm{Sn}-\mathrm{SS}-600$ & 254 & 79.5 & 99.4 & 79.0 \\
\hline Zn ${ }_{1}$ Sn-Evp-600 & 216 & 76.1 & 99.2 & 75.5 \\
\hline
\end{tabular}

[a] Reaction conditions: glycerol $=2 \mathrm{~g}$, urea $=1.31 \mathrm{~g}$, catalyst $=0.33 \mathrm{~g}$, temperature $=155^{\circ} \mathrm{C}$, time $=4 \mathrm{~h}$, under $\mathrm{N}_{2}$ bubbling, [b] from TPD analysis (sum of acidity and basicity). GlyC = glycerol carbonate.

(2-oxo-1,3-dioxolan-4-yl)methylcarbamate, and 5-(hydroxymethyl)-1,3-oxazolidin-2-one.

The $\mathrm{Zn}$-Sn composite oxides exhibited higher catalytic activity than the individual oxides. Among the composite oxides, higher activity depended on the specific catalyst preparation 
procedure adopted. $\mathrm{Zn}_{1} \mathrm{Sn}$-CoPre-600 catalyst gave $88 \%$ of glycerol conversion with approximately $99 \%$ selectivity for glycerol carbonate. In addition, $\mathrm{Zn}_{1} \mathrm{Sn}-\mathrm{SS}-600$ and $\mathrm{Zn}_{1} \mathrm{Sn}$-Evp600 gave $79.5 \%$ and $76 \%$, respectively, with $99.2 \%$ glycerol carbonate selectivity. Amongst the $\mathrm{Zn}-\mathrm{Sn}$ composite oxides, $\mathrm{Zn}_{1} \mathrm{Sn}$-CoPre-600 gave the best performance considering the glycerol carbonate yield. The superior catalytic activity is mainly attributed to the presence of higher amount of active sites (see Table 2). The lower activities of $\mathrm{ZnO}, \mathrm{SnO}_{2}$, and $\mathrm{Zn}_{2} \mathrm{SnO}_{4}$ compared to that of the composite oxides are mainly caused by the lower amount of active sites present in the catalyst. As a correlation, an enhanced catalytic activity in $\mathrm{Zn}_{1} \mathrm{Sn}$ composite oxide catalyst was observed with the increase of both acidic and basic site. The yield of glycerol carbonate over $\mathrm{Zn}_{1} \mathrm{Sn}$ catalysts prepared through different routes decreased with decrease in the amount of active sites in the following trend: Zn ${ }_{1}$ Sn-CoPre-600 > Zn, Sn-SS-600 > Zn ${ }_{1}$ Sn-Evp-600.

\section{Effect of Zn content in Zn-Sn composite oxides}

The $\mathrm{Zn}$-Sn composite oxides prepared through coprecipitation method exhibited high catalytic activity for glycerol carbonate synthesis. Therefore, the effect of $\mathrm{Zn} / \mathrm{Sn}$ molar ratio on the catalytic activity was investigated from $Z n / S n=1$ to 3 . The increase of $\mathrm{Zn}$ content in $\mathrm{Zn}-\mathrm{Sn}$ composite oxide resulted in a substantial improvement in glycerol conversion from $88 \%$ $\left(\mathrm{Zn}_{1} \mathrm{Sn}\right.$-CoPre-600) to $96 \%\left(\mathrm{Zn}_{2} \mathrm{Sn}-\mathrm{CoPre}-600\right)$ with $\geq 99 \%$ selectivity for glycerol carbonate as shown in Table 3 . Further in-

\begin{tabular}{|c|c|c|c|c|}
\hline Catalyst & $\begin{array}{l}\text { Total active } \\
\text { sites } \\
{\left[\mu \mathrm{molg}{ }^{-1}\right]^{[b]}}\end{array}$ & $\begin{array}{l}\text { Glycerol } \\
\text { conversion } \\
\text { [wt \%] }\end{array}$ & $\begin{array}{l}\text { GlyC } \\
\text { selectivity } \\
\text { [wt \%] }\end{array}$ & $\begin{array}{l}\text { GlyC } \\
\text { yield } \\
\text { [wt \%] }\end{array}$ \\
\hline $\mathrm{Zn}_{1} \mathrm{Sn}-\mathrm{CoPre}-600$ & 287 & 88.0 & 99.2 & 87.3 \\
\hline $\mathrm{Zn}_{2} \mathrm{Sn}$-CoPre-600 & 329 & 96.0 & 99.6 & 95.6 \\
\hline $\mathrm{Zn}_{3} \mathrm{Sn}$-CoPre-600 & 304 & 90.7 & 98.7 & 89.5 \\
\hline $\mathrm{Zn}_{2} \mathrm{Sn}-\mathrm{SS}-600$ & 268 & 84.0 & 99.2 & 83.3 \\
\hline $\mathrm{Zn}_{2} \mathrm{Sn}-\mathrm{Evp}-600$ & 258 & 80.0 & 99.0 & 79.2 \\
\hline
\end{tabular}

[a] Reaction conditions: Glycerol $=2 \mathrm{~g}$, urea $=1.31 \mathrm{~g}$, catalyst $=0.33 \mathrm{~g}$, temperature $=155^{\circ} \mathrm{C}$, time $=4 \mathrm{~h}$, under $\mathrm{N}_{2}$ bubbling, [b] From TPD analysis (sum of acidity and basicity). GlyC $=$ glycerol carbonate.

crease of $\mathrm{Zn}$ content from 2 to $3\left(\mathrm{Zn}_{3} \mathrm{Sn}\right.$-CoPre-600) resulted in a marginal decrease of glycerol conversion by approximately $5 \%$ and a minor decrease in glycerol carbonate selectivity. The enhanced catalytic activity of $\mathrm{Zn}_{2} \mathrm{Sn}$-CoPre-600 catalyst could be the result of the presence of higher amount of active sites than for other catalysts.

The catalysts prepared by the other two methods with best composition of $\mathrm{Zn} / \mathrm{Sn}=2$ were also evaluated for the synthesis of glycerol carbonate and compared with $\mathrm{Zn}_{2} \mathrm{Sn}$-CoPre-600 prepared by coprecipitation. These catalysts, $\mathrm{Zn}_{2} \mathrm{Sn}-\mathrm{SS}-600$ and $\mathrm{Zn}_{2} \mathrm{Sn}$-Evp-600, showed lower catalytic activity (84 and $80 \%$ conversion, respectively) than $\mathrm{Zn}_{2} \mathrm{Sn}$-CoPre-600 owing to the presence of lower amount of active sites.

\section{Effect of the calcination temperature of most active $\mathrm{Zn}_{2} \mathrm{Sn}$ - CoPre catalyst on the catalytic activity}

It is well known that the calcination temperature of metal oxides has an influence on composition, surface area, and active sites of the catalyst. Therefore, the effect of calcination temperature of $\mathrm{Zn}_{2} \mathrm{Sn}$-CoPre was studied by varying the calcination temperature ranging from 500 to $1000^{\circ} \mathrm{C}$. The catalytic activity of the calcined catalysts was evaluated and the results are depicted in Figure 4. The glycerol conversion increased ap-

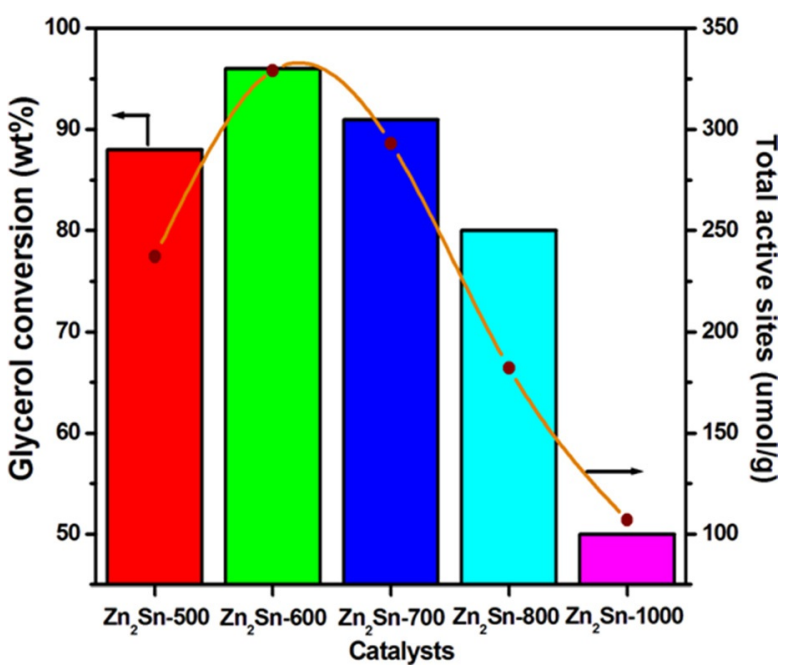

Figure 4. Effect of calcination temperature on catalytic activity. Reaction conditions: glycerol $(2 \mathrm{~g})$, urea $(1.31 \mathrm{~g})$, catalyst $(0.33 \mathrm{~g}), T=155^{\circ} \mathrm{C}, t=4 \mathrm{~h}$, under $\mathrm{N}_{2}$ bubbling.

preciably from 88.5 to $96 \%$ upon increasing calcination temperature from 500 to $600^{\circ} \mathrm{C}$ along with an increase in glycerol carbonate selectivity ( 98.5 to $99.6 \%$ ). However, with further increasing calcination temperature from 600 to $1000^{\circ} \mathrm{C}$, the catalytic activity decreased considerably (glycerol conversion decreased from 96 to $50 \%$ ). To understand the catalytic behavior of the catalysts calcined at different temperatures, the physicochemical properties and their relationship with catalytic performance were studied (see Table 1). It is found that the amount of total active sites decreased with increasing calcination temperature from 600 to $1000^{\circ} \mathrm{C}$, and $\mathrm{Zn}_{2} \mathrm{Sn}$-CoPre- 600 possesses more total active sites than other catalysts. The decrease in active sites upon increase of calcination temperature could be attributed to the decrease of surface area owing to the agglomeration of particles resulting in less surface metaloxygen pairs. ${ }^{[22]}$ The relationship between total active sites of the catalyst and their catalytic activity towards glycerol conversion is depicted in Figure 4. The enhanced catalytic behavior of $\mathrm{Zn}_{2} \mathrm{Sn}$-CoPre-600 was mainly attributed to the presence of a higher amount of total active sites compared to other catalysts.

\section{Influence of the reaction conditions}

The reaction temperature has a profound effect on the catalytic behavior. Therefore, a systematic study using $\mathrm{Zn}_{2} \mathrm{Sn}$-CoPre600 catalyst was conducted from 145 to $175^{\circ} \mathrm{C}$ with the glycer- 
ol/urea mole ratio of $1: 1$ and $10 \mathrm{wt} \%$ of catalyst. Glycerol conversion increased significantly from 78.5 to $96 \%$ with an increase in temperature from 145 to $155^{\circ} \mathrm{C}$ with a marginal increase of glycerol carbonate selectivity (98.7 to $99.6 \%$ ) as shown in Figure 5 a. Glycerol conversion and glycerol carbonate selectivity decreased marginally with further increase in reaction temperature from 165 to $175^{\circ} \mathrm{C}$. Therefore, $155^{\circ} \mathrm{C}$ was the best reaction temperature and hence it was selected for further studies.

The effect of catalyst amount towards glycerol carbonate synthesis was studied by using $\mathrm{Zn}_{2} \mathrm{Sn}$-CoPre- 600 from 5 to $15 \mathrm{wt} \%$ of total reactant weight as shown in Figure $5 \mathrm{~b}$. As the catalyst amount increased from 5 to $10 \mathrm{wt} \%$, the glycerol conversion increased significantly from 82 to $96 \%$ with an increase in glycerol carbonate selectivity (98.2 to $99.6 \%$ ) attributed to the increase in the number of accessible active sites. The conversion remained almost the same with further increase in catalyst amount to 12.5 and $15 \mathrm{wt} \%$. Hence, $10 \mathrm{wt} \%$ of catalyst loading is sufficient to yield high amount of glycerol carbonate and hence selected for further studies.
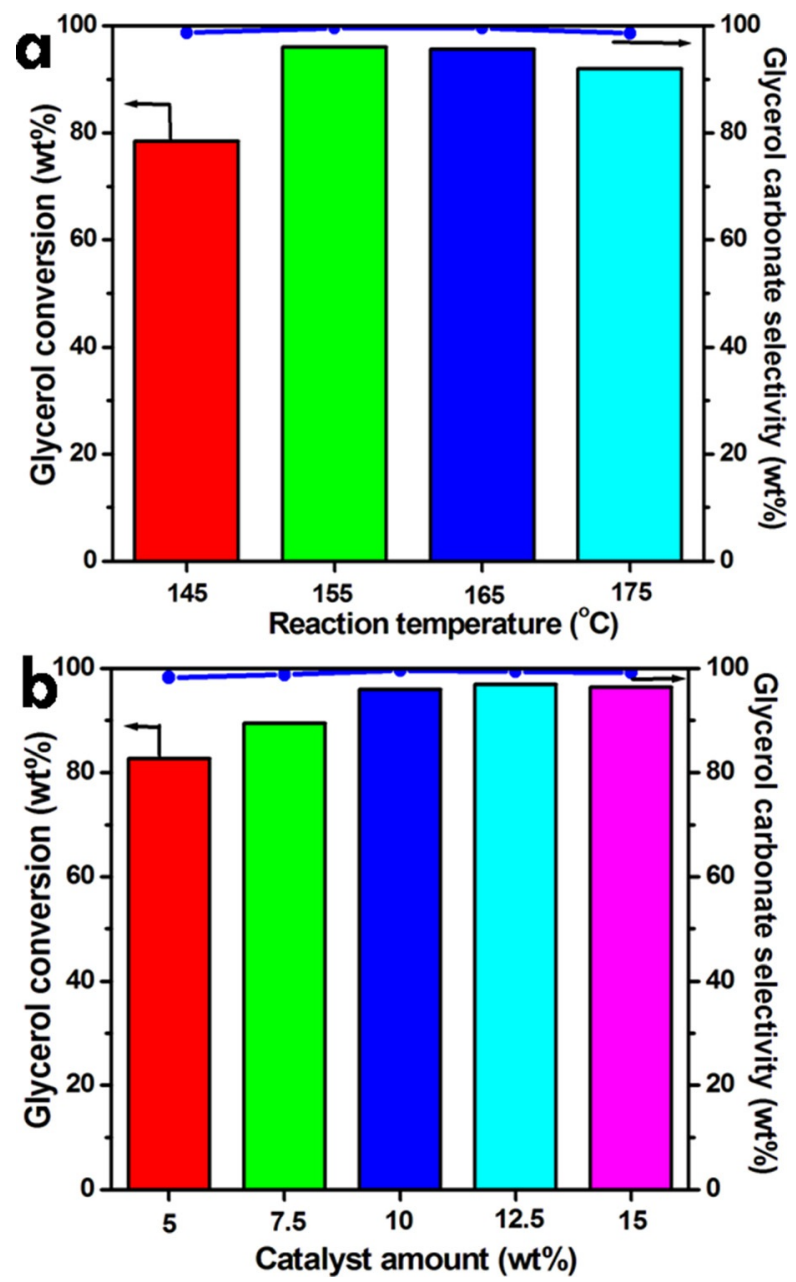

Figure 5. Influence of reaction conditions over glycerol carbonylation. (a) Effect of temperature: Reaction conditions: glycerol $(2 \mathrm{~g})$, urea $(1.31 \mathrm{~g})$, catalyst $(0.33 \mathrm{~g}) \mathrm{Zn}_{2} \mathrm{Sn}$-CoPre- $600, t=4 \mathrm{~h}$, under $\mathrm{N}_{2}$ bubbling;(b) effect of catalyst amount: reaction conditions: glycerol $(2 \mathrm{~g})$, urea $(1.31 \mathrm{~g})$, catalyst $Z \mathrm{n}_{2} \mathrm{Sn}$ CoPre- $600, T=155^{\circ} \mathrm{C}, t=4 \mathrm{~h}$, under $\mathrm{N}_{2}$ bubbling.
The effect of reaction time on the synthesis of glycerol carbonate was studied under the optimized reaction conditions. The results showed a significant increase in glycerol conversion with increase in reaction time as shown in the Supporting Information, Figure S.1.2. Initially it gave $50 \%$ conversion after $1 \mathrm{~h}$, which further increased to $96 \%$ after $4 \mathrm{~h}$ with a marginal increase in glycerol carbonate selectivity (98 to $99.6 \%$ ).

\section{Recycling studies}

The most active $\mathrm{Zn}_{2} \mathrm{Sn}$-CoPre-600 catalyst was studied for its reusability and the results are presented in Figure $6 \mathrm{a}$. The $\mathrm{Zn}_{2} \mathrm{Sn}$-CoPre-600 catalyst was tested under optimized reaction conditions for five consecutive runs (Fresh, R-1, R-2, R-3, and R4). After each run, the catalyst was filtered and washed with methanol to remove the adsorbed reactants on the catalyst surface. The catalyst was dried and finally calcined at $600^{\circ} \mathrm{C}$ for $4 \mathrm{~h}$. $\mathrm{Zn}_{2} \mathrm{Sn}$-CoPre-600 catalyst showed good recyclability with marginal decrease in the activity as shown in Figure $6 \mathrm{a}$. The yield for glycerol carbonate was $95.6 \%$ after the first cycle and it decreased marginally to $90.6 \%$ after 5 cycles. These results suggest that the $\mathrm{Zn}_{2} \mathrm{Sn}$-CoPre- 600 catalyst is stable and reusable without any appreciable loss in activity. The structural integrity of the recycled catalyst was examined by X-ray diffraction as shown in Figure $6 \mathrm{~b}$. The XRD pattern of the spent $\mathrm{Zn}_{2} \mathrm{Sn}$-CoPre-600 catalyst matched well with the characteristic peaks of fresh catalyst indicating no change in the structure of the catalyst even after five consecutive cycles.

To determine the leached zinc species during the reaction, atomic absorption spectroscopy (AAS) was performed. After the completion of reaction, the reaction medium was filtered and the filtrate was subjected to AAS. It showed a small amount of zinc dissolved $(\approx 1 \%)$ in the reaction mixture attributed to the formation of zinc glycerolate, which is commonly observed for $\mathrm{ZnO}$-containing catalysts. ${ }^{[22]}$

\section{Comparison of $\mathrm{Zn}-\mathrm{Sn}$ composite oxide with reported solid acid catalysts}

The catalytic performance of $\mathrm{Zn}$-Sn composite oxide was compared with that of other solid catalysts reported in the literature as shown in Table 4. The acid catalysts namely Sn-beta, ${ }^{[8]}$ $\mathrm{Au} / \mathrm{Fe}_{2} \mathrm{O}_{3}{ }^{[3]}$ and $\mathrm{Sm}_{0.66} \mathrm{TPA}^{[14]}$ showed high glycerol conversion with lower glycerol carbonate selectivity and vice versa observed with $\mathrm{Zn}_{1} \mathrm{TPA}^{\left[{ }^{[15]}\right.} 2.5 \% \mathrm{Au} / \mathrm{Nb}_{2} \mathrm{O}_{5}{ }^{[13]}$ and $\mathrm{Sn}-\mathrm{W}$ mixed oxide. $^{[8]}$ The catalysts containing acid-base property, specifically zirconium phosphate ${ }^{[9]}$ and $\mathrm{ZnSn}(\mathrm{OH})_{6,}{ }^{[16]}$ exhibited approximately $100 \%$ glycerol carbonate selectivity with high glycerol conversion. The zinc-exchanged HY zeolite ${ }^{[17]}$ showed $94.6 \%$ glycerol conversion with $98 \%$ selectivity to glycerol carbonate. The performance of $\mathrm{Zn}-\mathrm{Sn}$ composite oxide catalyst $\left(\mathrm{Zn}_{2} \mathrm{Sn}\right.$ CoPre-600) in the present study was at par with the best of the reported catalysts. 

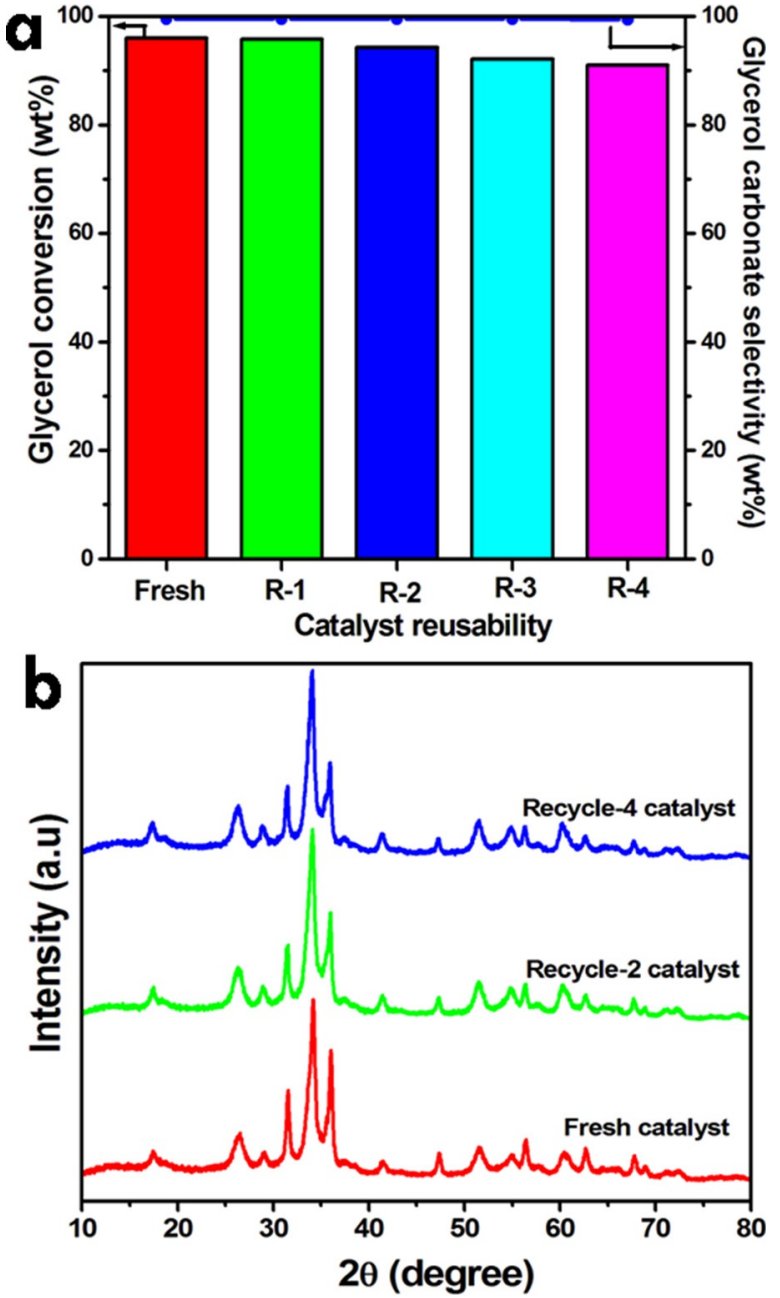

Figure 6. (a) Recycling of $\mathrm{Zn}_{2} \mathrm{Sn}$-CoPre- 600 catalyst for the carbonylation reaction. Reaction conditions: glycerol $(4 \mathrm{~g})$, urea ( $2.62 \mathrm{~g})$, catalyst amount $=0.66 \mathrm{~g}, T=155^{\circ} \mathrm{C}$, time $=4 \mathrm{~h}$, under $\mathrm{N}_{2}$ bubbling, (b) XRD patterns of recycled catalyst ( $\left.\mathrm{Zn}_{2} \mathrm{Sn}-\mathrm{CoPre}-600\right)$.

\section{Reaction mechanism}

It was found that the synthesis of cyclic carbonates from alcohol and urea is catalyzed by the combination of Lewis acid and Lewis base sites present in the catalyst. Based on the above findings, a plausible reaction mechanism is proposed for $\mathrm{Zn}$-Sn composite oxide catalyzed carbonylation of glycerol with urea and shown in Scheme 1. In the first step, the basic sites present in $\mathrm{Zn}-\mathrm{Sn}$ catalyst activate the hydroxyl group of glycerol, whereas the Lewis acidic Zn activates the carbonyl group of urea. In the second step, the lone pair of electron present on the hydroxyl group of glycerol attacks the carbonyl carbon and forms an intermediate with the elimination of ammonia. In the last step, this intermediate undergoes cyclization by the attack of adjacent hydroxyl group on the tertiary carbocation leading to the formation of glycerol carbonate with the elimination of another molecule of ammonia.

\section{Conclusions}

Zinc-Tin composite oxide catalysts were synthesized by three different methods and evaluated for the synthesis of glycerol carbonate by carbonylation of glycerol with urea. The composite oxide contained three components, namely, $\mathrm{Zn}_{2} \mathrm{SnO}_{4}, \mathrm{ZnO}$, and $\mathrm{SnO}_{2}$. These catalysts showed high activity towards the selective synthesis of glycerol carbonate compared to individual oxides. Zn-Sn composite oxide catalyst prepared from coprecipitation showed excellent catalytic performance compared to the catalysts prepared by other methods. The superior catalytic activity of the $\mathrm{Zn}-\mathrm{Sn}$ composite catalyst prepared by coprecipitation method ( $\mathrm{ZnSn}$-CoPre) is mainly attributed to the presence of high amounts of acidic and basic sites. The activity of $\mathrm{Zn}-\mathrm{Sn}$ composite oxide catalysts depends upon the $\mathrm{Zn} / \mathrm{Sn}$ mole ratio as well as calcination temperature. The better catalytic activity was obtained over the catalyst with the $\mathrm{Zn} / \mathrm{Sn}$ mole ratio of 2 calcined at $600^{\circ} \mathrm{C}$. A good correlation between the catalytic activity and the amount of active sites was observed. Thus, bifunctional $\mathrm{Zn}_{2} \mathrm{Sn}$-CoPre- 600 catalyst is shown to be the novel and highly efficient catalyst for cabonylation of glycerol with urea.

\section{Experimental Section}

\section{Catalyst preparation}

Preparation of $\mathrm{Zn}$-Sn composite oxides, method A (coprecipitation route): In a typical procedure for $\mathrm{Zn} / \mathrm{Sn}$ molar ratio of 2 , anhydrous

\begin{tabular}{|c|c|c|c|c|c|c|}
\hline \multirow[t]{2}{*}{ Catalyst } & \multirow{2}{*}{$\begin{array}{l}T \\
{\left[{ }^{\circ} \mathrm{C}\right]}\end{array}$} & \multirow{2}{*}{$\begin{array}{l}\text { Reaction } \\
\text { time [h] }\end{array}$} & \multirow{2}{*}{$\begin{array}{l}\text { Glycerol } \\
\text { conv. [\%] }\end{array}$} & \multicolumn{2}{|c|}{ Glycerolcarbonate [\%] } & \multirow[t]{2}{*}{ Ref. } \\
\hline & & & & Selectivity & Yield & \\
\hline SW21 & 140 & 4 & 52.1 & 95.3 & 49.7 & [10] \\
\hline Sn-beta & 145 & 5 & 70.0 & 37.0 & 25.9 & [8] \\
\hline $\mathrm{Zr}-\mathrm{P}$ & 140 & 3 & 80.0 & 100 & 80.0 & [9] \\
\hline $\mathrm{Au} / \mathrm{Fe}_{2} \mathrm{O}_{3}$ & 150 & 4 & 80.0 & 48.0 & 38.4 & [13] \\
\hline $2.5 \% \mathrm{Au} / \mathrm{Nb}_{2} \mathrm{O}_{5}$ & 150 & 4 & 66.0 & 32.0 & 21.1 & [13] \\
\hline $\mathrm{Sm}_{0.66} \mathrm{TPA}$ & 140 & 4 & 49.5 & 85.4 & 42.3 & [14] \\
\hline $\mathrm{Zn}_{1} \mathrm{TPA}$ & 140 & 4 & 69.2 & 99.4 & 68.8 & [15] \\
\hline $\mathrm{ZnSn}(\mathrm{OH})_{6}$ & 165 & 5 & 98.0 & 99.6 & 97.6 & [16] \\
\hline $\mathrm{La}_{2} \mathrm{O}_{3}$ & 140 & 4 & 68.9 & 98.1 & 67.6 & {$[11]$} \\
\hline $\mathrm{Zn}_{2} \mathrm{Sn}-\mathrm{CoPre}-600$ & 155 & 4 & 96.0 & 99.6 & 95.6 & this work \\
\hline
\end{tabular}




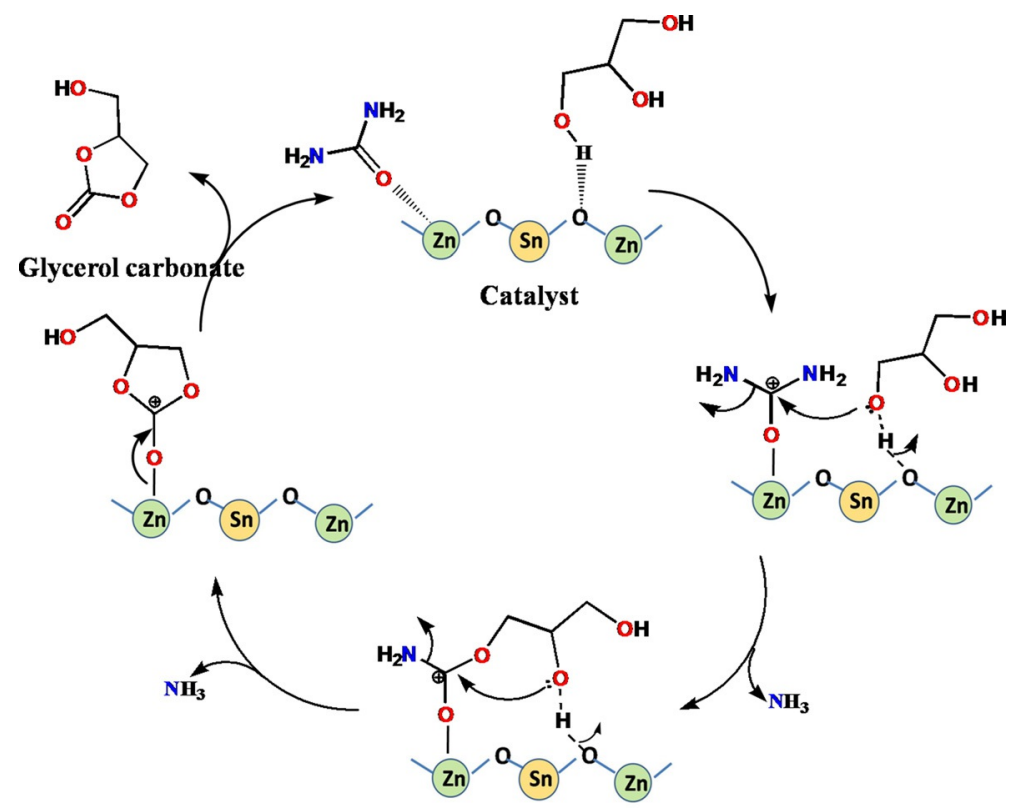

Scheme 1. Plausible reaction mechanism for the synthesis of glycerol carbonate over $\mathrm{Zn}-\mathrm{Sn}$ catalyst.

$\mathrm{ZnCl}_{2}(6.81 \mathrm{~g}, 1 \mathrm{M})$ and $\mathrm{SnCl}_{4} \cdot 5 \mathrm{H}_{2} \mathrm{O}(8.76 \mathrm{~g}, 0.5 \mathrm{M})$ were dissolved in $50 \mathrm{~mL}$ of deionized water followed by dropwise addition of $83 \mathrm{~mL}$ of $4 \mathrm{M} \mathrm{NaOH}$ solution. The precipitate was stirred for $3 \mathrm{~h}$ at RT, filtered, washed with deionized water until it was free from chloride and dried at $120^{\circ} \mathrm{C}$ overnight. The dried catalyst was subjected to calcination at $5^{\circ} \mathrm{Cmin}^{-1}$ for $4 \mathrm{~h}$ under static air and designated as $Z_{n} S n-y-z$ ( $x=$ zinc to tin mole ratio, $y=$ synthesis route, $z=$ calcination temperature in ${ }^{\circ} \mathrm{C}$ ). The above sample was thus designated as $\mathrm{Zn}_{2} \mathrm{Sn}$-CoPre-z.

$\mathrm{Zn}$-Sn composite oxide with different $\mathrm{Zn} / \mathrm{Sn}$ molar ratios $(\mathrm{Zn} / \mathrm{Sn}=$ 1 , and 3) were prepared by changing the molar ratios of the starting metal salt solutions and sodium hydroxide concentration. The hydroxides obtained were subjected to calcination at $600^{\circ} \mathrm{C}$ for $4 \mathrm{~h}$ under static air. The catalysts are denoted as $\mathrm{Zn}_{1} \mathrm{Sn}-\mathrm{CoPre}-600$ and $\mathrm{Zn}_{3}$ Sn-CoPre-600.

Preparation of $\mathrm{Zn}-\mathrm{Sn}$ composite oxides, method B (solid-state route): The mechanical mixtures of $\mathrm{ZnO}$ and $\mathrm{SnO}_{2}$ with molar ratios of 1:1 and 2:1 were prepared as follows. In a typical procedure, $\mathrm{ZnO}$ and $\mathrm{SnO}_{2}$ powders were taken with a required $\mathrm{Zn} / \mathrm{Sn}$ molar ratio $(=1$ or 2 ) and they were mechanically ground by using mortar and pestle for 30 min. Finally, the sample was subjected to calcination at $600^{\circ} \mathrm{C}$ for $4 \mathrm{~h}$ at $5^{\circ} \mathrm{Cmin}^{-1}$ under static air. The sample was designated as $\mathrm{Zn}_{x} \mathrm{Sn}-\mathrm{SS}-600$ (where $x=1$ or 2).

Preparation of $\mathrm{Zn}-\mathrm{Sn}$ composite oxides, method C (evaporation route): Zinc chloride and tin chloride salts with required mole ratio of $\mathrm{Zn} / \mathrm{Sn}(=1$ or 2 ) were dissolved in distilled water and allowed to evaporate to complete dryness. Later, the dried sample was subjected to calcination at $600^{\circ} \mathrm{C}$ for $4 \mathrm{~h}$ and the obtained sample was designated as $\mathrm{Zn}_{x} \mathrm{Sn}$-Evp-600 (with $x=1$ or 2).

Preparation of pure oxides: $\mathrm{ZnO}$ was prepared by precipitation route with the following procedure. $1 \mathrm{M} \mathrm{NaOH}$ solution $(83 \mathrm{~mL})$ was added dropwise to the beaker containing $50 \mathrm{~mL}$ of $0.5 \mathrm{M}$ aqueous $\mathrm{ZnCl}_{2}$ solution. The obtained precipitate was allowed to stir for $3 \mathrm{~h}$, filtered, washed, and dried at $120^{\circ} \mathrm{C}$ overnight. The dried product was ground into fine powder and calcined at $600^{\circ} \mathrm{C}$ for $4 \mathrm{~h}$. $\mathrm{SnO}_{2}$ was prepared with above-mentioned procedure with $2 \mathrm{M}$ concentration of $\mathrm{NaOH}$ and $0.5 \mathrm{M}$ aqueous $\mathrm{SnCl}_{4} \cdot 5 \mathrm{H}_{2} \mathrm{O}$.
Preparation of $\mathrm{Zn}_{2} \mathrm{SnO}_{4}: \mathrm{Zn}_{2} \mathrm{SnO}_{4}$ was prepared from the reported literature ${ }^{[24]}$ and calcined at $600{ }^{\circ} \mathrm{C}$ for $4 \mathrm{~h}$.

\section{Catalyst characterization}

Powder X-ray diffraction patterns of the catalysts were recorded with Bruker D2 phaser X-ray diffractometer using $\mathrm{Cu}_{\mathrm{k \alpha}}$ radiation $(\lambda=1.5418 \AA)$ with high resolution Lynxeye detector. All the samples were scanned in the $2 \theta$ range of $10-80^{\circ}$ with step size of $0.04^{\circ} \mathrm{s}^{-1}$. The specific surface area, pore volume and pore size of the catalysts were determined from nitrogen sorption measurement using Quantachrome NOVA instrument at $77 \mathrm{~K}$. The amount of acidity and basicity present in the catalysts were determined by TPD equipped with thermal conductivity detector (using $\mathrm{NH}_{3}$ and $\mathrm{CO}_{2}$, respectively). In all the experiments, the sample $(400 \mathrm{mg})$ was calcined at the desired temperature for $1 \mathrm{~h}$ in helium gas flow $\left(25 \mathrm{~mL} \mathrm{~min}{ }^{-1}\right.$ ) and then cooled to $50^{\circ} \mathrm{C}$. At $50^{\circ} \mathrm{C}$, the sample was saturated with $10 \%$ of ammonia or carbon dioxide in a helium stream for $2 \mathrm{~h}$. After the saturation of probe molecule, the sample was flushed with helium for $1 \mathrm{~h}$ at $50^{\circ} \mathrm{C}$ to remove the physisorbed probe molecule, and then desorption of ammonia or carbon dioxide was performed in the temperature range from 50 to $600^{\circ} \mathrm{C}$ with the heating rate of $8{ }^{\circ} \mathrm{Cmin}^{-1}$. SEM images of $\mathrm{Zn}-\mathrm{Sn}$ composite oxide catalysts prepared by different methods were recorded on Zeiss microscope to investigate the particle size and morphology. TEM analyses were performed using TEM-JEOL-2010 instrument.

\section{Catalytic activity studies}

The glycerol carbonylation reaction with urea was performed in a $50 \mathrm{~mL}$ 2-necked glass batch reactor equipped with a reflux condenser. In a typical experiment, the required amounts of glycerol $(2 \mathrm{~g})$ and urea $(1.31 \mathrm{~g})$ were taken along with preactivated catalyst (wt \% referred to total reactant weight). The reaction mixture was magnetically stirred at required temperature with bubbling of nitrogen gas through the second neck of glass reactor to remove the evolved ammonia gas during the reaction. After the desired 
time of reaction, the reaction mixture was dissolved in methanol and centrifuged to separate out the catalyst from the liquid phase. The obtained liquid was analyzed by gas chromatography (Agilent $7820 \mathrm{~A})$ equipped with a capillary column $(0.25 \mathrm{~mm}$ I.D and $60 \mathrm{~m}$ length, HP-INNOWAX) and flame ionization detector. The products were confirmed by GCMS analysis. The glycerol conversion and glycerol carbonate selectivity were calculated using the following formulae:

Glycerol conversion (wt \%)

$$
=\frac{\text { wt of glycerol taken }- \text { wt of unreacted glycerol }}{\text { wt of glycerol taken }} \times 100
$$

Product yield (wt \%)

$$
=\frac{\text { glycerol converted }(\mathrm{wt} \%) \times \text { product selectivity }}{100}
$$

\section{Acknowledgements}

GVS is thankful to Vision Group on Science and Technology, Govt. of Karnataka, India for Centre of Excellence in Science Engineering and Medicine (CESEM) Grant (GRD No 307). PM acknowledges Admar Mutt Education Foundation (AMEF), Bangalore for providing a scholarship and thankful to Manipal University for permitting this research as a part of the Ph.D. program. Authors are thankful to CeNSE, Indian Institute of Science, Bangalore for SEM analysis.

Keywords: biomass $\cdot$ carbonylation $\cdot$ green chemistry $\cdot$ tin $\cdot$ zinc

[1] C. Serrano-Ruiz, R. Luque, A. S. Escribano, Chem. Soc. Rev. 2011, 40, $5266-5281$.

[2] A. Behr, J. Eilting, K. Irawadi, J. Leschinsk, F. Linder, Green Chem. 2008, $10,13-30$.
[3] B. Zhang, G. Ding, H. Zheng, Y. Zhu, Appl. Catal. B 2014, 152-153, 226 232.

[4] M. J. Climent, A. Corma, S. Iborra, Green Chem. 2014, 16, 516-547.

[5] P. Manjunathan, S. P. Maradur, A. B. Halgeri, G. V. Shanbhag, J. Mol. Catal. A 2015, 396, 47-54.

[6] M. O. Sonnati, S. Amigoni, E. P. T. de Givenchy, T. Darmanin, O. Choulet, F. Guittard, Green Chem. 2013, 15, 283-306.

[7] J. R. Ochoa-Gómez, O. G. J. Aberasturi, C. R. Lopez, M. Belsue, Org. Process Res. Dev. 2012, 16, 389-399.

[8] M. J. Climent, A. Corma, P. D. Frutos, S. Iborra, M. Noy, A. Velty, P. Concepcion, J. Catal. 2010, 269, 140-149.

[9] M. Aresta, A. Dibenedetto, F. Nocito, C. Ferragina, J. Catal. 2009, 268, $106-114$.

[10] K. Jagadeeswaraiah, Ch. R. Kumar, P. S. S. Prasad, S. Loridant, N. Lingaiah Appl. Catal. A 2014, 469, $165-172$

[11] L. Wang, Y. Ma, Y. Wang, S. Liu, Y. Deng, Catal.Commun. 2011, 12, $1458-$ 1462.

[12] F. Rubio-Marcos, V. C. Casilda, M. A. Banares, J. F. Fernandez, ChemCatChem 2013, 5, $1431-1440$.

[13] C. Hammond, J. A. L. Sanchez, M. H. A. Rahim, N. Dimitratos, R. L. Jenkins, A. F. Carley, Q. He, C. J. Kiely, D. W. Knight, G. J. Hutchings, Dalton Trans. 2011, 40, 3927-3937.

[14] Ch. R. Kumar, K. Jagadeeswaraiah, P. S. S. Prasad, N. Lingaiah, ChemCatChem 2012, 4, 1360-1367.

[15] K. Jagadeeswaraiah, Ch. R. Kumar, P. S. S. Prasad, N. Lingaiah, Catal. Sci. Technol. 2014, 4, 2969-2977.

[16] S. Sandesh, G. V. Shanbhag, A. B. Halgeri, RSC Adv. 2014, 4, 974-977.

[17] V. S. Marakatti, A. B. Halgeri, RSC Adv. 2015, 5, 14286-14293.

[18] S. E. Kondawar, A. S. Potdar, C. V. Rode, RSC Adv. 2015, 5, 16452-16460.

[19] S. D. Lee, M. S. Park, D. W. Kim, I. Kim, D. W. Park, Catal. Today 2014, 232, $127-133$.

[20] M. B. Gawande, R. K. Pandey, R. V. Jayaram, Catal. Sci. Technol. 2012, 2, $1113-1125$.

[21] G. Parameswaram, M. Srinivas, H. Babu, P. S. S. Prasad, N. Lingaiah, Catal. Sci. Technol. 2013, 3, 3242-3249.

[22] H. Li, D. Gao, P. Gao, F. Wang, N. Zhao, F. Xiao, W. Wei, Y. Sund, Catal. Sci. Technol. 2013, 3, $2801-2809$.

[23] S. Yuvaraj, W. Jong Lee, C. W. Lee, R. K. Selvan, RSC Adv. 2015, 5, 67210 67219.

[24] M. B. Ali, F. B. Bouaifel, H. Elhouichet, B. Sieber, A. Addad, L. Boussekey M. Ferid, R. Boukherroub, J. Colloid Interface Sci. 2015, 457, 360-369.

Received: October 5, 2015

Published online on December 9, 2015 